\title{
Characterization of wheat (Triticum aestivum) for stay green trait
}

\author{
Naresh Pratap Singh* and Vaishali \\ Department of Biotechnology, SVP University of Agriculture and Technology, Meerut-250110 (U.P.), INDIA \\ *Corresponding author. E-mail: naresh.singh55@yahoo.com
}

Received: April 15, 2015; Revised received: September 21, 2015; Accepted: January 30, 2016

\begin{abstract}
Stay green trait is one of the major character of the crops like wheat, rice etc. to sustain under abiotic stresses. In the present study, 10 wheat varieties were collected to develop the stay green genotype by treating them with $0.5 \%$ Ethyl methanesulphonate (EMS) for 60 minutes. The various morphological and physiological characteristics such as: plant height, leaf area, numbers of productive tillers/plant, seeds per spike, 1000 grain weight, related water content (RWC), chlorophyll content etc. were recorded under controlled and treatment conditions. Exceptionally, K 7410 and RAJ 3765 varieties showed better value of all morpho-physiological characters among all the ten wheat varieties in control and treatment like 1000 grain weight 58.50 to $60.89 \mathrm{~g}$ and 56.89 to $58.07 \mathrm{~g}$ etc. Such mutants of these two varieties may be considered as stay green mutants and can perform better under abiotic stress conditions like drought, high temperature.
\end{abstract}

Keywords: Morphological parameters, Physiological characters, Stay green trait, Wheat

\section{INTRODUCTION}

Wheat (Triticum aestivum L.) is used mainly for human consumption and supports nearly $35 \%$ of the world population by providing $55 \%$ of the carbohydrates and $20 \%$ of the food calories consumed globally (Breiman and Graur, 1995). In India, 29\% of the total cultivable area faces drought condition out of which $10 \%$ is under severe drought (Anonymous, 2003). Drought and water shortages threaten the agricultural productivity of many developing countries to feed their ever growing population. In addition Abiotic stresses such as extreme temperature, drought, heat, salinity, mineral deficiency and toxicity are frequently encountered by plants in both natural and agricultural systems. The abiotic stresses are estimated to reduce yields to less than a half of that possible under ideal growth conditions. In addition abiotic stress reactions, especially to water deficiency and high level of salts, are complex morphological and physiological phenomenon in plants (Wang et al., 2003). Drought stress not only affects the morphology but also severely affects the metabolism of the plant, physiology and biochemical responses in plants. These responses include stomatal closure, repression of cell growth and photosynthesis and activation of respiration Therefore, physiological and biological approaches have a great importance in order to understand the complex responses of plants to water deficiency and to develop new varieties.

The plant growth and productivity are greatly affected by abiotic stresses such as drought, salinity, and temperature (Hussain et al, 2011). High temperature stress is a major yield limiting factor adversely affecting wheat development and growth and causes low yield in many regions of the world (Modarresi et al., 2010). Vegetative growth and the reproductive phase in wheat differ in their sensitivity to temperature (Chakrabarti et al., 2011). Heat stress reduces photosynthesis through disruptions in the structure and function of chloroplasts, and reductions in chlorophyll content (Xu et al., 1995), therefore, can be used as stress indicator for screening.

One approach to achieve a longer photosynthetic period is the use of functional stay-green phenotypes, which show either a delayed onset or a slower rate of senescence with maintaining photosynthetic activity (Xu et al., 2000). The 'stay green' phenotype can arise in different ways. Many mutations, referred to as stay green have been reported to maintain leaf greenness after the grain-ripening stage (Walulu et al., 1994; Fang et al., 1998; Spano et al., 2003). Some 'stay green' mutants can photosynthesize longer and might therefore be expected to give a higher yield; these may be defined as 'functional stay green' mutants. In China a functional stay-green phenotype was developed with increased grain yield and total biomass under field conditions (Luo et al., 2006). The stay-green trait has been reported to increase yields (Gong et al., 2005; Luo et al., 2006), and there were positive correlations to water use efficiency (G'orny and Garczy' nski, 2002; Christopher et al., 2008), spot blotch resistance (Joshi et al., 2007) and yields under heat and drought (Naruoka et al., 2012). Therefore, the present research was carried out to characterize the wheat(Triticum aestivum) for stay green trait. 


\section{MATERIALS AND METHODS}

The present research work was carried out at Department of Biotechnology, College of Agriculture, of S.V.P. University of Agriculture and Technology, Meerut during rabi season. A total of ten varieties of wheat viz. HUW 510, C 306, Sonalika, HD 2135, HD 2177, VL 401, K 9162, RAJ 3765, K 68, K 7410 were collected and subjected to Ethyl methanesulphonate(EMS) treatment for developing stay green mutants. The seeds of all ten varieties were treated with Ethyl methanesulphonate $(0.5 \%$ in distill water $)$ for 60 minutes in petri plates. Thereafter the treated seeds of wheat were sown in pots and various morphopysiological characters were studied as explained below.

Morphological evaluation of wheat varieties: The five plants from each variety were randomly selected for measuring the various characters. The data was observed for pre-harvest characters like plant height (total height of plant), number of productive tiller, leaf area (of flag leaf), days of maturity (days from sowing to the $98-100 \%$ loss of total chlorophyll content of plant). For post-harvest characters the data was recorded for length of spike (ear length is measured in $\mathrm{cm}$.), number of spikelets per spike (mean of 5 spikes per genotypes is considered for analysis), seeds per spike (Mean of seeds counted from 5 randomly sampled spikes at maturity is recorded for analysis), thousand grain weight (in gm.) were recorded from control and treatment plants for comparative study.

Physiological evaluation of wheat varieties: After inducing mutation by Ethyl methanesulphonate(EMS) for developing stay green trait the data for various physiological characters as related water content (RWC), chlorophyll content and photosynthetic rate was recorded. The RWC was measured on the wheat seedling organs following the method of Turner (1981). Fresh weight (FW) of flag leaf was determined immediately after harvest, and then tissue were allowed to float in distilled water until fully rehydrated. The wheat organs were weighted for turgid weight (TW). The turgid organs were dried in a hot oven at 80 ${ }^{\circ} \mathrm{C}$ to constant weight, and dry weight (DW) was recorded. The RWC was calculated as:

$\mathrm{RWC}(\%)=(\mathrm{FW}-\mathrm{DW}) /(\mathrm{TW}-\mathrm{DW}) * 100$.

Chlorophyll meter (SPAD 520) were used to measures the relative chlorophyll content $\left(\mu \mathrm{gm} / \mathrm{cm}^{2}\right)$ of the leaves and Infra Red Gas Analyzer (IRGA) was used to measure the photosynthetic rate of leaves ( $\mu \mathrm{mol} /$ $\mathrm{m}^{2} \mathrm{sec}$ ). Five readings were taken from five plant leaves of same variety and their average was considered for determination of RWC, Chlorophyll content and Photosynthetic rate.

Statistical analysis: The experimental data were compiled by taking mean values over randomly selected plant from both replications and subjected to the statistical analysis. The analysis of variance for the design of the experiment was carried out according to the procedure outlined by Panse and Sukhatme (1978). The significance of differences among treatment means was tested by ' $\mathrm{F}$ ' test and ANOVA.

\section{RESULTS AND DISCUSSION}

In the present investigation, attempts were made to characterize identify the stay green trait in mutants of some wheat genotypes based on the morphological and physiological characters in control and after EMS treatment $(0.5 \%$ for 60 minutes.). The data was recorded from three replicates of control and treatment.

Morphological characterization of wheat varieties under control and treated condition

Pre-harvest characteristics: Plant height was recorded at final stage of maturity. The plant height was found to be increased after the treatment of Ethyl methanesulphonate(EMS)(Table 1). In control plants Sonalika and RAJ 3765 varieties showed higher value $95 \mathrm{~cm}$ but after treatment Sonalika showed highest plant height $97 \mathrm{~cm}$, whereas the variety K 7410 and RAJ 3765 showed decrement in plant height. The number of productive tillers per plant was varied from 8.58 in $\mathrm{K} 7410$ to 6.47 in HD 2177 in controlled plants. The number of productive tillers decreases after treatment except in K 7410 and RAJ 3765 variety. Leaf area of flag leaf is directly related to higher photosynthesis and high chlorophyll content. The leaf area of flag leaf in controlled plants was varied from 33.17 to $23.03 \mathrm{~cm}^{2}$ in variety $\mathrm{K} 7410$ and C 306 . Total leaf area of flag leaf of wheat varieties was reduced significantly after EMS treatment except in variety $\mathrm{K} 7410$ and RAJ 3765. Overall the varieties took 135 to 146 days to get mature. After EMS treatment, days to maturity increased as compared to control. Variety K 7410 and RAJ 3765 took lesser time to get mature after EMS treatment so, it could be considered as stay green genotype. On the other hand, the longest time taken by variety HD 2135 in control i.e. 146 days and 148days after the EMS treatment.

Post-harvest characteristics: In the present study, the significant variations were reported in 1000 grain weight and numbers of grains per spike amongst different varieties after treatment of Ethyl methanesulphonate(EMS). The length of spike varied from $11.33 \mathrm{~cm}$ in $\mathrm{K} 7410$ to $8.20 \mathrm{~cm}$ in HD 2177 variety in control plants but after treatment of EMS the spike length reduces significantly except in variety $\mathrm{K} 7410$ (Table 2). The number of spiklets/spike varied from 23.12 in K 7410 to 15.63 in HD 2177 in control plants. The number of spiklets/spikes in most of the varieties reduced after the treatment of EMS except in variety $\mathrm{K}$ 7410 and RAJ 3765. A seeds per spike are direct measure of yield/plant, hence it is economically important post harvest characteristic. The number of seeds per spike was decreasing after EMS treatment in almost all the varieties except in variety K 7410 and RAJ 3756. It was found to be increased from 61.17 (control) to 
Table 1.Pre-harvest characteristics of wheat (Mean values of three replicates).

\begin{tabular}{|c|c|c|c|c|c|c|c|c|c|}
\hline \multirow[t]{2}{*}{ S.N. } & \multirow[t]{2}{*}{ Genotypes } & \multicolumn{2}{|c|}{ Plant Height (cm) } & \multicolumn{2}{|c|}{ 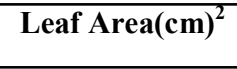 } & \multicolumn{2}{|c|}{$\begin{array}{c}\text { No. of productive } \\
\text { Tiller }\end{array}$} & \multicolumn{2}{|c|}{ Days To Maturity } \\
\hline & & $\mathrm{C}$ & $T$ & $\mathrm{C}$ & $T$ & $\mathrm{C}$ & $T$ & $\mathrm{C}$ & $T$ \\
\hline 1 & HUW 510 & 86.33 & 93.50 & 29.8 & 28.77 & 9.37 & 8.83 & 143 & 145 \\
\hline 2 & C 306 & 87.25 & 92.08 & 23.03 & 22.87 & 8.23 & 6.30 & 143 & 145 \\
\hline 3 & Sonalika & 95.00 & 97.00 & 25.13 & 23.26 & 7.58 & 6.17 & 136 & 139 \\
\hline 4 & HD 2135 & 86.67 & 90.67 & 26 & 24.37 & 8.17 & 6.83 & 143 & 148 \\
\hline 5 & HD 2177 & 81.57 & 87.58 & 25.1 & 23.67 & 6.47 & 7.25 & 140 & 143 \\
\hline 6 & VL 401 & 90.17 & 93.17 & 27.97 & 24.24 & 8.50 & 7.67 & 139 & 144 \\
\hline 7 & K 9162 & 89.13 & 92.17 & 25.03 & 22.48 & 8.52 & 7.50 & 142 & 145 \\
\hline 8 & RAJ 3765 & 95.00 & 91.00 & 32.47 & 33.73 & 9.37 & 10.08 & 139 & 134 \\
\hline 9 & K 68 & 88.98 & 94.83 & 30.03 & 27.24 & 8.42 & 6.72 & 141 & 143 \\
\hline 10 & K 7410 & 86.67 & 84.42 & 33.17 & 36.03 & 8.58 & 10.13 & 135 & 132 \\
\hline
\end{tabular}

$\mathrm{C}=$ Control, $\mathrm{T}=$ Treatment $(0.5 \%$ for 60 minutes of EMS $)$

Table 2. Post-harvest characteristics of wheat (Mean values of three replicates).

\begin{tabular}{|c|c|c|c|c|c|c|c|c|c|}
\hline \multirow[t]{2}{*}{ S.N. } & \multirow[t]{2}{*}{ Genotypes } & \multicolumn{2}{|c|}{$\begin{array}{c}\text { Length } \\
\text { of Spike }(\mathrm{cm})\end{array}$} & \multicolumn{2}{|c|}{ Spikelets/spike } & \multicolumn{2}{|c|}{ Seeds/Spikes } & \multicolumn{2}{|c|}{$\begin{array}{l}1000 \text { Grain weight } \\
\text { (g) }\end{array}$} \\
\hline & & $\mathbf{C}$ & $\mathbf{T}$ & $\mathbf{C}$ & $\mathbf{T}$ & $\mathbf{C}$ & $\mathbf{T}$ & $\mathbf{C}$ & $\mathbf{T}$ \\
\hline 1 & HUW 510 & 10.30 & 9.37 & 18 & 16.67 & 46.33 & 45.34 & 47.50 & 46.34 \\
\hline 2 & C 306 & 10.67 & 9.80 & 20.33 & 17.67 & 49.5 & 47.67 & 42.70 & 40.30 \\
\hline 3 & Sonalika & 10.90 & 7.41 & 20.67 & 18.33 & 50.33 & 46.33 & 44.00 & 39.80 \\
\hline 4 & HD 2135 & 10.03 & 10.53 & 21.67 & 19.67 & 51.37 & 48.33 & 45.20 & 42.10 \\
\hline 5 & HD 2177 & 8.20 & 8.70 & 15.63 & 15.67 & 45.84 & 40.67 & 46.30 & 42.80 \\
\hline 6 & VL 401 & 10.13 & 9.30 & 22.67 & 21.67 & 56.67 & 53 & 40.20 & 42.13 \\
\hline 7 & K 9162 & 10.80 & 11.47 & 21.67 & 18.67 & 50.33 & 45.78 & 47.70 & 44.07 \\
\hline 8 & RAJ 3765 & 12.08 & 12.37 & 22.43 & 23.83 & 60.07 & 62.17 & 56.89 & 58.07 \\
\hline 9 & K 68 & 10.93 & 10.83 & 22 & 20.67 & 58.33 & 54.67 & 50.20 & 47.23 \\
\hline 10 & K 7410 & 11.33 & 12.00 & 23.12 & 25.08 & 61.17 & 63.00 & 58.50 & 60.89 \\
\hline
\end{tabular}

$\mathrm{C}=$ Control, $\mathrm{T}=$ Treatment $(0.5 \%$ for 60 minutes of EMS $)$

63.00 (treatment) and 60.07 (control) to 62.17( treatment) respectively. 1000 Grain Weight showed the actual yield of the crop in the field. A significant reduction in test weight was observed after treatment of EMS. The weight of 1000 grain varied from higher value of $58.50 \mathrm{~g}$ in $\mathrm{K} 7410$ variety to lower value of $40.20 \mathrm{~g}$ in VL 401 variety in control plants. The variety K 7410 and RAJ 3765 showed significantly increment in test weight in comparison to other varieties after the treatment. In present study, significant reduction in yield components like spikelet per spike, grain yield were observed in mutated genotypes than control. However, the variety K 7410 and RAJ 3765 shows increase in above said characters form control to mutants genotypes. This type of results suggests that these two varieties (K 7410 and RAJ 3765) can perform better under abiotic stress conditions. This was supported by the results reported by Khakwani et al., 2011 in his experiment on six bread wheat varieties under induced drought stress condition. Genotypes with good tolerance to abiotic stresses have a stable or long duration of photosynthetic activity by maintaining RWC and chlorophyll contyent. The mutants developed in the present work having stay-green trait help in the increase of yield of crops, supported by Gong et al., 2005 and Christopher et al., 2008 in their water stress inducing experiment in wheat. The positive correlations between water use efficiency, photosynthesis and yields under the effect of heat and drought stress in wheat was reported by Naruoka et al., 2012 and G'orny and Garczy' nski, 2002. Similarly, in the present work also the direct relation between RWC, photosynthesis and yield were observed. Extending the duration of chlorophyll content, carbon and nitrogen is a possible means to increase total photosynthesis, biomass and yield in wheat, maize etc. (Richards, 2000).

Physiological characterization of wheat varieties under control and treatment condition: The Relative water content (RWC) will help the plant to withhold water and supply to plant for its normal functioning in unfavorable conditions. The RWC in controlled plants varied from $60.30 \%$ in $\mathrm{K} 7410$ to $24.29 \%$ in Sonalika. The increased RWC after EMS treatment was observed in variety $\mathrm{K} 7410$ and RAJ 3765 from 60.30 to $63.00 \%$ and from 59.69 to $62.73 \%$ and thus could be considered as stay green genotype which may be suitable for growing in abiotic stressed environment (Table 3). Ganji et al. (2012), also reported that the plants having higher yields under drought and heat stress should have high RWC as it greatly affected by these stresses. The chlorophyll content is one of the essential parameter among all of the observed parameters and can be considered as indicator of stay green genotypes. Chlorophyll content was found to be highest in K 7410 and lowest in 39.10 in HD 2135 in control. The chlorophyll content of variety $\mathrm{K} 7410$ is in- 
Table 3. Physiological parameters of wheat (Mean values of three replicates) .

\begin{tabular}{|c|c|c|c|c|c|c|c|}
\hline \multirow[t]{2}{*}{ S.N } & \multirow[t]{2}{*}{ Genotypes } & \multicolumn{2}{|c|}{ RWC (\%) } & \multicolumn{2}{|c|}{ Chlorophyll $\left(\mu \mathrm{gm} / \mathrm{cm}^{2}\right)$} & \multicolumn{2}{|c|}{$\begin{array}{c}\text { Photosynthesis rate } \\
\left(\mu \mathrm{mol} / \mathrm{m}^{2} \mathrm{sec}\right)\end{array}$} \\
\hline & & $\bar{C}$ & $\mathbf{T}$ & $\mathbf{C}$ & $\mathbf{T}$ & $\mathbf{C}$ & $\mathbf{T}$ \\
\hline 1 & HUW 510 & 56.07 & 55.23 & 48.40 & 47.35 & 16.80 & 15.78 \\
\hline 2 & C 306 & 29.43 & 26.40 & 45.97 & 42.87 & 15.40 & 16.03 \\
\hline 3 & Sonalika & 26.29 & 24.55 & 40.10 & 39.05 & 17.43 & 16.89 \\
\hline 4 & HD 2135 & 55.19 & 53.25 & 39.10 & 39.02 & 17.67 & 16.83 \\
\hline 5 & HD 2177 & 36.37 & 33.23 & 39.87 & 38.87 & 18.17 & 16.33 \\
\hline 6 & VL 401 & 27.40 & 24.37 & 41.63 & 39.87 & 18.10 & 17.33 \\
\hline 7 & K 9162 & 49.49 & 44.48 & 45.97 & 41.55 & 17.83 & 17.17 \\
\hline 8 & RAJ 3765 & 59.69 & 62.73 & 48.25 & 50.88 & 22.00 & 23.07 \\
\hline 9 & K 68 & 59.44 & 54.60 & 43.58 & 42.23 & 19.10 & 18.33 \\
\hline 10 & K 7410 & 60.30 & 63.91 & 50.58 & 53.83 & 22.43 & 24.80 \\
\hline
\end{tabular}

$\mathrm{C}=$ Control, $\mathrm{T}=$ Treatment $(0.5 \%$ for 60 minutes of EMS $)$

creases significantly after the treatment of EMS from 50.58 to $53.83 \mu \mathrm{g} / \mathrm{cm}^{2}$. Rest of the variety showed significant decrement in chlorophyll content after the treatment. The photosynthesis rate varied from 15.40 $\mu \mathrm{mol} / \mathrm{m}^{2}$ sec in C 306 to $22.43 \mu \mathrm{mol} / \mathrm{m}^{2}$ sec in $\mathrm{K} 7410$ in control. The photosynthesis rate was found to be increased in $\mathrm{K} 7410$ and RAJ 3765 from 22.43 to $24.80 \mu \mathrm{mol} / \mathrm{m}^{2} \mathrm{sec}$ and from 22.00 to $23.07 \mu \mathrm{mol} / \mathrm{m}^{2} \mathrm{sec}$ respectively after the treatment of EMS but showed a significant reduction in photosynthetic rate after the treatment. Such profile of photosynthesis rate indicates that variety K 7410 and RAJ 3765 could be considered as stay green mutants. Increase in physiological traits could simultaneously increase yield traits in water stress conditions. Similarly, Gupta et al., (2001) research on wheat supports the present work that physiological traits and yield attributes of crops are related directly related eachother. It means there is a greater scope of using physiological traits in selection for improving yield in wheat. Total flag leaf photosynthesis, chlorophyll content, the onset of senescence, and green leaf duration have all been found to be positively correlated with wheat grain yield (Wang et al., 2008; Gaju et al., 2011). Increased chlorophyll content leads to increase in yield showed by K 7410 and RAJ 3765 after three treatments of EMS. Khayatnezhad et al. (2011) reported similar results in corn cultivars (Zea mays) and concluded that the genotypes with high leaf chlorophyll content are tolerant to stress conditions.

\section{Conclusion}

The present investigation also support the abiotic stress tolerance of the K 7410 and RAJ 3765 based on developing stay green trait i.e. long duration of photosynthesis by maintaining longer leaf chlorophyll content, delayed leaf senescence after treatment of EMS. By understanding the role of stay green trait in several major crops may be the key to overcome the productivity loss under unfavorable abiotic environmental stresses. Morphological characters such as plant height, leaf area, seeds per spike, 1000 grain weight etc. are an important parameters for better yield of crops so they are economically important characters. In present work all morphological characters were found to be decreased except in variety K7410 and RAJ3765 which showed better results after the EMS treatment. In the same way, physiological characters such as relative water content (RWC), chlorophyll and photosynthesis were also an important partameters for the crops to withstand in abiotic stressed environment which directly results in better yield. Here also K7410 and RAJ3765 varieties showed highest value of these characteristics after the treatment of EMS among all wheat varieties taken. Such results suggested that the treatment $(0.5 \%$ EMS $)$ of mutagen may be benificial for developing stay green trait in major crops to give better yield in abiotic stressed environment.

\section{REFERENCES}

Anonymous, (2003). Agriculture Statistics. Vol. 1, Ministry of Jehad-e-Agriculture, Tehran, Iran.

Breiman, A. and Graur, D. (1995). Wheat Evolution. Israel Jour. Pl. Sci., 43: 85-98.

Chakrabarti, B., Singh, S.D., Nagarajan, S. and Aggarwal, P.K. (2011). Impact of temperature on phenology and pollen sterility of wheat varieties. Aust. J. Crop Sci., 5 (8): 1039-1043.

Christopher, J.T., Manschadi, A.M., Hammer, G.L. and Borrell, A.K. (2008). Developmental and physiological traits associated with high yield and stay-green phenotype in wheat. Australian Journal of Agricultural Research, 59: 354-364.

Fang, Z., Bouwkamp, J.C. and Solomos, T. (1998). Chlorophyllase activities and chlorophyll degradation during leaf senescence in the non-yellowing mutant and the wild-type of Phaseolus vulgaris L. J. Exp. Bot. 49: 503 -510 .

G'orny, A.G. and Garczy', nski S. (2002) Genotypic and nutrition-dependent variation in water use efficiency and photosynthetic activity of leaves in winter wheat (Triticum aestivum L.). J. Appl. Genet., 43: 145-160.

Gaju, O., Allard, V., Martre, P., Snape, J.W., Heumez, E., Le Gouis, J., Moreau, D., Bogard, M., Griffiths, S., Orford, S., Hubbart, S. and Foulkes, M.J. (2011). Identification of traits to improve the nitrogen-use efficiency of wheat genotypes. Field Crops Research. 123: 139-152.

Ganji, A.F., Jabbari, R. and Morshedi, A. (2012). Evaluation of Drought Stress on Relative Water Content, Chlorophyll Content and Mineral Elements of Wheat (Triticum 
aestivum L.) varieties. IJACS /4-11/726-729.

Gong, Y.H., Zhang J., Gao, J.F., Lu, J.Y. and Wang, J.R. (2005). Slow export of photoassimilate from stay-green leaves during late grain-filling stage in hybrid winter wheat (Triticum aestivum L.). Journal of Agronomy and Crop Science. 191: 292-299.

Gupta, N.K., Gupta, S. and Kumar, A. (2001). Effect of water stress on physiological attributes and their relationship with growth and yield of wheat cultivars at different stages. J. Agron. Crop Sci., 186: 55-62.

Hussain, S.S., Mahmood, A.K., and Muhammad, A. (2011). Transcription factors as tools to engineer enhanced drought stress tolerance in plants. Biotechnology Progress., 27(2): 297-306.

Joshi, A.K., Kumari, M., Singh, V.P., Reddy, C.M. Kumar, S., Rane, J. and Chand, R. (2007). Stay green trait: variation, inheritance and its association with spot blotch resistance in spring wheat (Triticum aestivum L.). Euphytica. 153: 59-71.

Khakwani A.A., Dennett M.D. and Munir M. (2011). Early growth response of six wheat varieties under artificial osmotic stress condition. Pak. J. Agric. Sci., 48: 121126.

Khayatnezhad, M., Gholamin, R., Jamaati-e- Somarin, S.H. and Zabihie-Mahmoodabad, H. (2011). The leaf chlorophyll content and stress resistance relationship considering in Corn cultivars (Zea mays). Adv. Environ. Biol., 5 (1): 118-122.

Luo, P.G., Ren, Z.L., Wu, X.H., Zhang, H.Y., Zhang, H.Q. and Feng, J. (2006). Structural and biochemical mechanism responsible for stay green phenotype in common wheat. Chin. Sci. Bull., 51: 25952603.

Modarresi, M., Mohammdi, V., Zali, A. and Mardi, M. (2010). Response of wheat yield and yield related traits of high temperature. Cereal Research communications, 38(1): 23-31
Naruoka, Y., Sherman, J.D., Lanning, S.P., Blake, N.K., Martin, J.M. and Talbert, L.E. (2012) Genetic analysis of green leaf duration in spring wheat. Crop Sci., 52, 99 -109 .

Panse V.G and Sukhatme P.V. (1978). Statistical methods for agricultural workers ICAR, New Delhi. 145-150.

Richards, R.A. (2000). Selectable traits to increase crop photosynthesis and yield of grain crops. J. Exp. Bot., 51: 447-458.

Spano, G., Fonzo, N.Di., Perrotta, C., Platani, C., Ronga, G., Lawlor, D.W., Napier, J.A. and Shewry, P.R. (2003). Physiological characterization of 'stay green' mutants in durum wheat. Journal of Experimental Botany, 54: 386.

Turner, N.C. (1981). Techniques and experimental approaches for the measurement of plant water status. Plant and Soil, 58: 339-366.

Walulu, R.S., Rosenow, D.T., Wester, D.B. and Nguyen, H.T. (1994). Inheritance of the stay-green trait in sorghum. Crop Sci., 34: 970-972.

Wang, H., McCaig, T.N., DePauw, R.M. and Clarke, J.M. (2008). Flag leaf physiological traits in two highyielding Canada Western Red Spring wheat cultivars. Can. J. Plant Sci., 88: 35-42.

Wang, W., Vinocur, B. and Altman, A. (2003). Plant responses to drought, salinity and extreme temperatures: towards genetic engineering for stress tolerance. Planta ., 218: 1-14.

Xu, Q., Paulsen, A. Q., Guikema, J. A. and Paulsen, G.M. (1995). Functional and ultrastructural injury to photosynthesis in wheat by high temperature during maturation. Environ. Exp. Bot., 35: 43-54

$\mathrm{Xu}$, W., Rosenow, D.T. and Nguyen, H.T. (2000). Staygreen trait in grain sorghum: Relationship between visual rating and leaf chlorophyll concentration. Plant Breeding., 119: 365-36. 